\title{
Multimodality Therapy
}

National Cancer Institute

\section{Source}

National Cancer Institute. Multimodality Therapy. NCI Thesaurus. Code C15212.

Use of two or more simultaneous or consecutive treatment modalities; e.g., surgery + radiation, or radiation + immunotherapy. Does not refer to use of two or more chemotherapeutic agents. 